\title{
Comparison of R-CHOPwith CHOP in Patients of Diffuse Large B Cell Lymphoma
}

\author{
Faiza Rehman Lodhi, ${ }^{1}$ Amjad Zafar, ${ }^{2}$ Muhammad Abbas Khokhar, ${ }^{3}$ Ali Waheed Goraya, ${ }^{4}$ Sonia Ashraf, \\ Sobia Yaqub ${ }^{6}$
}

\begin{abstract}
Objective: Diffuse large B cell lymphoma (DLBCL) is a lymphoid B cells neoplasm with a diffuse pattern and high proliferation rate. Cyclophosphamide, doxorubicin, vincristine and prednisolone (CHOP) was considered effective as other complicated regimens with more toxicity profile. Rituximab is a monoclonal antibody directed against CD20 positive B cell. It has good activity therapeutically in patients of DLBCL. It increases response rates and survivals when added to CHOP chemotherapy. Although R-CHOP is more effective but due to high cost of Rituximab it is usually not incorporated with chemotherapy in most of our patients and CHOP is still used extensively. Due to heterogeneity of disease and difference in ethnicity, there may be difference in outcomes of two regimens. This study will help us in tailoring our management plan that will result in better outcome of patients.

Methods: 70 patients aged between 20-65 years having DLBCL were taken in this study. We rando-mized patients by lottery method into two groups. Group I received CHOP with dose of Cyclophosphamide $750 \mathrm{mg} / \mathrm{m} 2$, Doxorubicin $50 \mathrm{mg} / \mathrm{m} 2$, Vincristine $1.4 \mathrm{mg} / \mathrm{m} 2$ and prednisolone $40 \mathrm{mg} / \mathrm{m} 2$.Chemotherapy was given on Day-1 while prednisolone was given for 5 days from Day-1 of chemotherapy. Group II received RCHOP which includes same chemotherapy with same dosage. Rituximab was included in Group II with dose of Rituximab $375 \mathrm{mg} / \mathrm{m} 2$. Each cycle was given at three weeks interval. Response in terms of CR (Complete Response), PR (Partial Response), SD (Stable Disease) or PD (Progressive Disease) was evaluated as per leukemia network after 4 cycles of chemotherapy. The quantitative variables were calculated by taking mean and standard deviation. The response was assessed in percentage and frequencies and compared by applying chi square test.

Results: Group I had 37.1\% while Group II had 68.6\% complete response with p value of 0.019 . Partial response was $48.6 \%$ in Group I while $20.0 \%$ in Group II. $14.3 \%$ in Group I and $8.6 \%$ in Group II either had stable disease or progressive disease.

Conclusions: R-CHOP has superior response rates as compared to $\mathrm{CHOP}$, therefore, whenever possible Rituximab should be added as target therapy in chemotherapy.

Key Words: Diffuse large B cell lymphoma, CHOP, R- CHOP

How to Cite: Lodhi F.R, Zafar A, Khokhar M.A, Goraya AW, AshrafS, Yaqub S. Comparison of R-CHOP with CHOP in patients of diffuse large B cell lymphoma. Esculapio.2020;16(04):79-82.

DOI: https://doi.org/10.51273/esc20.2516417
\end{abstract}

\section{Introduction}

$\mathrm{A}^{\mathrm{n}}$ mong non-Hodgkin's lymphomas, DLBCL is most common type present approximately $25 \%$ in the developed countries ${ }^{1}$. Based on morphology of

\footnotetext{
1. Faiza Rehman Lodhi

3. Muhammad Abbas Khokhar

5. Sonia Ashraf

1-4: Department of Oncology, King Edward Medical University, Lahore

5. Department of Pathology, King Edward Medical University

6. Department of Oncology

Correspondence:

Dr. Faiza Rehman Lodhi, Senior Registrar, Oncology Department King

Edward Medical University, Lahore.Email: Faizarehman@hotmail.com

Submission Date:
1st Revision Date:
Acceptance Date:

Submission Date:
1st Revision Date:
Acceptance Date:

Submission Date:
1st Revision Date:
Acceptance Date: 05-11-2020 10-11-2020 04-12-2020

2. Amjad Zafar

4. Ali Waheed Goraya

6. Sobia Yaqub
}

lymphoid tissue and immunophenotyping pathological diagnosis of DLBCL can be made. CHOP was considered effective as other complicated regimens with more toxicity profile based on number of serial clinical investigations ${ }^{2}$. DLBCL is a heterogeneous variety of tumors having large $\mathrm{B}$ cells that are transformed and having prominent nucleoli. Cells of DLBCL have basophilic cytoplasm, diffuse pattern of growth and high proliferation rate. Tumor cells in DLBCL expresses B cell antigens (CD19, CD20, CD22 and CD79a). Rituximab is monoclonal antibody directed against $\mathrm{CD} 20$ positive $\mathrm{B}$ cells. It has good activity therapeutically in patients of DLBCL. R-CHOP which includes Rituximab with CHOP 
chemotherapy is more effective therapy and has better responses and survivals. ${ }^{3}$ Rituximab when incorporated with chemotherapy showed survival benefit in the GELA Trial. It also increase survival in British Columbia trial when added to CHOP chemotherapy. ${ }^{4,5}$ There was no difference in response rate between R-CHOP and CHOP in another study but there was a significant difference in relapse rates between these groups. ${ }^{5}$ This was in contrast to result of another study conducted on elderly patients, where the response rate was also increased with R-CHOP. ${ }^{3}$ In a study, $\mathrm{Li} X$ et al analyzed retrospectively 437 patients of DLBCL who were newly diagnosed. In six university hospitals they received CHOP or R-CHOP therapy and followed up for assessment of response after treatment. Between R-CHOP and CHOP, significant differences in overall survival and progressionfree survival were present. Median follow up was of 86 month in this study. Overall survival was $84.1 \%$ in R-CHOP group and $70.2 \%$ in CHOP group with $\mathrm{p}$ value of 0.018 . While progression free survival was $81.5 \%$ in R-CHOP group and $66.7 \%$ in CHOP group with $\mathrm{p}$ value of 0.015 . In this study, elderly patients with age greater than 60 years received higher overall survival as compared to younger population. Median follow up was 66 months in elderly population with overall survival $80.7 \%$ in R-CHOP group and $53.0 \%$ in CHOP group with $p$ value of 0.011 . Chemotherapy with rituximab did not showed significant effect on overall survival that is $85.5 \%$ in R-CHOP and $79.4 \%$ in CHOP group with $\mathrm{p}$ value of $0.428 .^{6} \mathrm{In}$ another study by Afzar $\mathrm{M}$ et al showed CR for CHOP Group as $44.4 \%$ and for R-CHOP group as $48.2 \%$ while PR as $11.1 \%$ for CHOP group and $7.1 \%$ for R-CHOP. ${ }^{7}$ Although R-CHOP is more effective but due to high cost of Rituximab it is usually not incorporated with chemotherapy in most of our patients and CHOP is still used extensively. There may be difference in outcomes of two regimens due to heterogeneity of disease and difference in ethnicity. This study will help us in in better outcome of patients by tailoring our management plan.

\section{Methods}

After taking approval from hospital ethical committee, patients who fulfilled the selection criteria were enrolled and written informed consent was taken from them before commencement of treatment. Patients were randomized by lottery method into two groups. Group I received CHOP with dose of Cyclophosphamide $750 \mathrm{mg} / \mathrm{m}^{2}$, Doxorubicin $50 \mathrm{mg} / \mathrm{m}^{2}$, Vincristine $1.4 \mathrm{mg} / \mathrm{m}^{2}$ and prednisolone $40 \mathrm{mg} / \mathrm{m}^{2}$. Chemotherapy was given on Day-1 while prednisolone was given for 5 days from Day-1 of chemotherapy. Group II received R-CHOP which includes same chemotherapy with same dosage. Rituximab was included in Group II with dose of Rituximab 375 $\mathrm{mg} / \mathrm{m}^{2}$. Each cycle was given at three weeks interval. Response in terms of CR (Complete Response), PR (Partial Response), SD (Stable Disease) or PD (Progressive Disease) is evaluated as per Lugano criteria with CT scan after four cycles of chemotherapy. We ensured follow up by taking patient's contact number. All the information was recorded on Performa by me. Data was entered on SPSS (Statistical Package of Social Sciences), version-10 software after being collected on Performa. Quantitative variables (age) were presented as mean and standard deviation. Qualitative variables (stage and disease response) were presented as frequency and percentage. Comparison between groups was made by applying chisquare test. We stratified the data for age, gender and stage of disease to describe effect modifiers. Chisquare test was used after stratification to assess significance with $\mathrm{p}<.05$ as statistical significance.

\section{Results}

70 subjects were randomly divided into Group I $(\mathrm{CHOP} \mathrm{n}=35)$ and Group II (RCHOP $\mathrm{n}=35)$. Mean age of subjects was 45.24 years, SD 13.31 with minimum age of 20 years and maximum age of 78 years. $57.1 \%$ in Group I and $48.6 \%$ in Group II were of age $20-50$ years and $49.2 \%$ in Group I and $51.4 \%$ in Group II were of age $51-80$ years. $31.4 \%$ were females and $68.6 \%$ were male in Group I, $42.8 \%$ were females and $57.2 \%$ were male in Group II. $11.4 \%$ in Group I and 17.1\% in Group II were in stage-1. 11.4\% in Group I and $22.9 \%$ in Group II were in stage-2. $37.1 \%$ in Group I and $17.1 \%$ in Group II were in stage- $3.40 .0 \%$ in Group I and $42.9 \%$ in Group II were in stage- $4.42 .9 \%$ in Group I and $20.0 \%$ in Group II have no extra nodal involvement, $42.9 \% \%$ in Group I and $62.9 \%$ in Group II had one extra nodal involvement and $8.6 \%$ in Group I and $17.1 \%$ in Group II had 2 extra nodal involvements. $37.1 \%$ in Group I and $42.9 \%$ in Group II had low risk (0-1), 28.6\% in Group I and $17.1 \%$ in Group II were having low intermediate risk, $22.9 \%$ in Group I and $17.1 \%$ in Group II were having high interme-diate risk $(=3)$ and 
$11.4 \%$ in Group I and $22.9 \%$ in Group II were having high risk (4-5). 28.6\% in Group I and 51.4\% in Group II had comorbidities. Final outcome was compared among groups, $37.1 \%$ in group I and $68.6 \%$ in Group II had complete res-ponse with $\mathrm{P}<.019$ which was statistically significant. $48.6 \%$ in group I and $20.0 \%$ in Group II had partial response, $5.7 \%$ in group I and $0.0 \%$ in Group II had a stable response, and $8.6 \%$ in both groups had progressive disease.

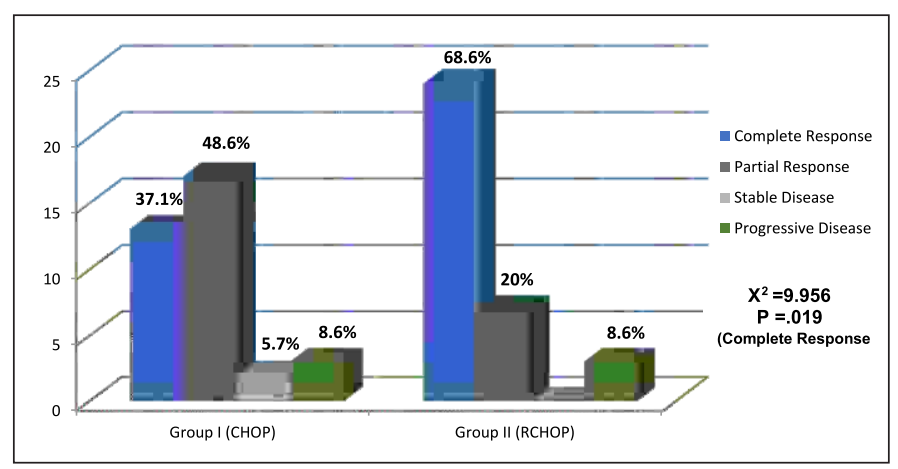

Figure 1: Final Outcome of Treatment Among Groups

Table 1: Demographic Data of Patients included in the study.

\begin{tabular}{|c|c|c|}
\hline \multirow{2}{*}{ AGE (Years) } & \multicolumn{2}{|c|}{ Groups } \\
\hline & Group I & Group II \\
\hline Mean Age & 46.6 & 49.6 \\
\hline Median Age & 47.00 & 52.00 \\
\hline Std. Deviation & 14.485 & 11.950 \\
\hline Minimum & 21 & 22 \\
\hline Maximum & 70 & 72 \\
\hline \multirow{2}{*}{ An ARBOR STAGING } & \multicolumn{2}{|c|}{ Groups } \\
\hline & Group I & Group II \\
\hline STAGE1 & $4(11.4 \%)$ & $6(17.1 \%)$ \\
\hline STAGE2 & $4(11.4 \%)$ & $8(22.9 \%)$ \\
\hline STAGE 3 & $13(37.1 \%)$ & $6(17.1 \%)$ \\
\hline STAGE4 & $14(40.0 \%)$ & $15(42.9 \%)$ \\
\hline \multirow{2}{*}{ EXTRANODAL SITE } & \multicolumn{2}{|c|}{ Groups } \\
\hline & Group I & Group II \\
\hline$\leq 1$ SITE INVOLVEMENT & $30(85.8 \%)$ & $29(82.9 \%)$ \\
\hline$\geq 2$ SITE INVOLVEMENT & $5(14.2 \%)$ & $6(17.1 \%)$ \\
\hline \multirow{2}{*}{ IPI SCORE } & \multicolumn{2}{|c|}{ Groups } \\
\hline & Group I & Group II \\
\hline $\begin{array}{l}\text { 0-2 LOW \& LOW } \\
\text { INTERMEDIATE RISK }\end{array}$ & $23(65.7 \%)$ & $21(60 \%)$ \\
\hline $\begin{array}{l}3-5 \text { HIGH \& HIGH } \\
\text { INTERMEDIATE RISK }\end{array}$ & $12(34.3 \%)$ & $14(40 \%)$ \\
\hline \multirow{2}{*}{ COMORBIDITIES } & \multicolumn{2}{|c|}{ Groups } \\
\hline & Group I & Group II \\
\hline No & $25(71.4) \%$ & $17(48.6 \%)$ \\
\hline Yes & $10(28.6 \%)$ & $18(51.4 \%)$ \\
\hline
\end{tabular}

\section{Discussion}

DLBCL is the commonest variety of non-Hodgkin's lymphoma. It is clinically very heterogeneous lymphoma. Only $40 \%$ patients show good responses to current therapy and have survival benefit, whereas others don't respond well. This clinical heterogeneity and difference in natural history is due to molecular heterogeneity among tumors. CHOP is standard chemotherapy for patients with DLBCL. Rituximab is monoclonal antibody directed against CD20 positive B cells. It has good activity therapeutically in patients of DLBCL. We conducted a randomized trial and compared responses of R-CHOP with CHOP in patients of DLBCL.

Rituximab when added to CHOP chemotherapy increases complete responses and survival of patients in older patients with diagnosis of DLBCL as per study by Coffier et al. There was no significant increase in toxicity seen with addition of Rituximab. ${ }^{3}$

Most of patients of DLBCL are of greater than sixty years. ${ }^{8}$ Only half of patients responded with $\mathrm{CHOP}$ chemotherapy which was considered standard for years for all age groups of DLBCL. ${ }^{10}$ Multiple attempts were made by adding other chemotherapy agents to increase the efficacy of therapy but it did not succeed. Regimens with increase doses of chemotherapy improve responses only in younger patients who have bad prognosis. ${ }^{11}$ These intensified therapies were not tolerated by elderly population of patients. CHOP is also sometimes not tolerated by elderly patients. For this purpose easily tolerated chemotherapy regimens were designed for old patients, but these are less beneficial as compared to CHOP. ${ }^{10}$

Rituximab is a monoclonal antibody directed against CD20 positive B cells, it was first given on relapse and refractory low grade lymphomas. It was then found to have activity in relapse and refractory DLBCL. ${ }^{12}$ CD20 is surface protein on lymphoid cells that is present only on mature B cells. The antibody is a chimeric because it is made up of human IgG1 portion with genetic engineered portion of mouse antibody which has CD20-binding site on it. Studies were conducted in which rituximab combined with CHOP chemotherapy showed 90 percent responses in all lymphomas. ${ }^{13}$ The Groupe d'Etude des Lymphomes de l'Adulte (GELA) group studied and compared $\mathrm{R}-\mathrm{CHOP}$ with $\mathrm{CHOP}$ in elderly population of patients with DLBCL. This was a randomized trial comparing both the effectiveness and safety of rituximab when 
combined with CHOP with CHOP alone in patients of DLBCL. Higher responses rates and survivals were found among patients of DLBCL treated with RCHOP. Patients treated with R-CHOP had fewer relapses after complete response and less rate of progression of disease that is why having longer survival. R-CHOP was tolerated well and no serious side effect was observed. In conclusion, R-CHOP chemotherapy when we give to elderly population of patients with newly diagnosed DLBCL increases responses to therapy, decreases failures with treatment and relapse of disease. It also improves survivals when compared with CHOP chemotherapy alone. There was no significant gain in toxicities with this addition.

\section{Conclusion}

R-CHOP has superior response rates as compared to CHOP, therefore, whenever possible Rituximab should be added as target therapy in chemotherapy.

\section{Conflict of Interest: $\quad$ None}

\section{References}

1. Kumar V AA, Fausto N, Aster J. Lymphoid neoplasms, Myeloid neoplasms. In: Shmitt W GR, editor. Pathologic Basis of Disease. 1. 8 ed. 1600 John F. Kennedy Blvd. Philadelphia, PA 19103-2899: SAUNDERS ELSEVIER; 2010. p. 589-674

2. Fisher RI, Gaynor ER, Dahlberg $\mathrm{S}$ et al. Comparison of a standard regimen (CHOP) With three intensive chemotherapy regimens for advanced non-Hodgkin's lymphoma. N Engl J Med 1993;328:1002-6.

3. Coiffier B, Lepage E, Briere J, Herrecht R, Tilly H, Bouabdallah $\mathrm{R}$ et al. CHOP chemotherapy plus rituximab compared with $\mathrm{CHOP}$ alone in elderly patients with diffuse large B cell lymphoma. N Engl J Med 2002;346:235-42.

4. Sehn LH, Donaldson J, Chhanabhai M et al. Introduction of combined CHOP plus rituximab therapy dramatically improves outcome of diffuse large B cell lymphoma in British Columbia .J Clin Oncol 2005; 23:5027-33.

5. Habermann TM, Weller EA, Morrison EA, Morrison VA et al. Rituximab-CHOP verses CHOP alone or with maintenance rituximab in older patients with diffuse large B-cell lymphoma .J Clin Oncol 2006; 24:3121-7.

6. Li X1, Liu Z, Cao J, Hong X, Wang J, Chen F, et al. Rituximab in combination with CHOP chemotherapy for the treatment of diffuse large B cell lymphoma in China: a 10-year retrospective follow-up analysis of 437 cases from Shanghai Lymphoma Research Group. Ann Hematol. 2012 Jun;91(6):837-45. doi: 10.1007/s00277-011-1375-0. Epub 2011 Dec 9.

7. Azfar M, Rizvi F, Siddiqui N et all. Phase II trial of CHOP vs R-CHOP chemotherapy in Pakistani Diffuse Large B cell lymphoma. Ann Pak Inst Med Sci 2010; 6(1):31-35.

8. The International Non-Hodgkin's Lymphoma Prognostic Factors Project. A predictive model for aggressive non-Hodgkin's lymphoma. N Engl J Med 1993; 329:987-994

9. Fisher RI, Gaynor ER, Dahlberg S, et al. Comparison of a standard regimen (CHOP) with three intensive chemotherapy regimens for advanced non-Hodgkin's lymphoma. N Engl J Med 1993;328:1002-1006

10. Sonneveld $\mathrm{P}$, de Ridder $\mathrm{M}$, van der Lelie $\mathrm{H}$, et al. Comparison of doxorubicin and mitoxantrone in the treatment of elderly patients with advanced diffuse non-Hodgkin's lymphoma using CHOP versus CNOP chemotherapy. J Clin Oncol 1995; 13:2530-2539

11. Haioun C, Lepage E, Gisselbrecht C, et al. Survival benefit of high-dose therapy in poor-risk aggressive non-Hodgkin's lymphoma: final analysis of the prospective LNH87-2 protocol -- a Groupe d'Etude des Lymphomes de l'Adulte study. J Clin Oncol 2000; 18:3025-3030

12. Maloney DG, Grillo-Lopez AJ, White CA, et al. IDEC-C2B8 (rituximab) anti-CD20 monoclonal antibody therapy in patients with relapsed low-grade non-Hodgkin's lymphoma. Blood 1997;90:21882195

13. Czuczman MS, Grillo-Lopez AJ, White CA, et al. Treatment of patients with low-grade B-cell lymphoma with the combination of chimeric anti-CD20 monoclonal antibody and CHOP chemotherapy. J Clin Oncol 1999;17:268-276

\section{Authors Contribution}

LRF: Article writing

ZA, KAM: Data Collection

GWA, AS, TS: Data analysis 